\title{
A LUTA DOS CATADORES DE MATERIAIS RECICLÁVEIS DE ALAGOAS
}

\author{
Emanuel Lucas de Barros \\ Mestre em Economia Aplicada \\ Universidade Federal de Alagoas (CMEA/UFAL), \\ Maceió, AL, Brasil. \\ elb.lucas@gmail.com
}

\begin{abstract}
Resumo - Este trabalho trata da organização coletiva dos catadores de materiais recicláveis de Alagoas. Categorias basilares acerca do desenvolvimento econômico, ecologia popular e economia solidária foram utilizadas a fim de elucidar o objeto de estudo. Como fonte de pesquisa foi consultada as informações disponibilizadas pela Secretaria de Estado do Meio Ambiente e Recursos Hídricos e a pesquisa empírica realizada com os grupos de catadores de recicláveis durante o Encontro Estadual em 2016. Foram identificados 14 empreendimentos de catadores em 11 municípios de Alagoas.
\end{abstract}

Palavras-chave: Economia Solidária; Ecologia Popular; Catadores de Materiais Recicláveis

\section{THE FIGHT OF RECYCLERS MATERIALS OF ALAGOAS}

\begin{abstract}
Abtract - This paper deals with the collective organization of waste pickers in Alagoas. Basic categories about economic development, popular ecology and solidarity economy were used in order to elucidate the object of study. As a research source, the information provided by the State Department of Environment and Water Resources and the empirical research carried out with the groups of recyclable waste pickers during the State Meeting in 2016. Fourteen waste collector organization were identified in 11 municipalities in Alagoas.
\end{abstract}

Keywords: Solidarity Eeconomy; Popular Ecology; Wasted Collectors.

\section{INTRODUÇÃO}

Tensões pelo acesso aos recursos naturais são cada vez mais recorrentes, e a necessidade do aumento da produção, de bens duráveis ou não, devido a lógica de acumulação capitalista, estimula a confrontação pelo uso da natureza. O sistema de mercado auto regulável tem se mantido hegemônico desde as primeiras revoluções industriais e, apesar de ter contribuído para o desenvolvimento das forças produtivas, tem gerado crises econômicas e ambientais sem precedentes, além de distúrbios como aumento do desemprego, da desigualdade de renda e social, e ainda, a exclusão da parcela menos abastada da sociedade do mercado formal de trabalho, aprofundando a problemática da relação capital-trabalho.

Os catadores de materiais recicláveis resistem a exclusão social e lutam pela manutenção e melhoria de seu ofício. Na busca do trabalho decente e do avanço na cadeia produtiva da reciclagem, através da coleta seletiva solidária, procuram a geração de emprego e renda, contribuindo com o meio ambiente, de onde surge em forma contraditória a consciência ambiental no processo em si e para si. 
O presente artigo busca caracterizar a prática solidária e ecológica realizada pelos catadores de materiais recicláveis de Alagoas. Por meio de formulação teórica buscou-se apreender algumas correntes ambientalistas e pontos de convergência com a economia solidária.

Para compreender a realidade desses empreendimentos solidários que emergem em meio ao que é rejeitado pela população, utilizaremos os conceitos de desenvolvimento econômico, ecologia popular e autogestão, redefinindo sua forma de participação e inserção social. Para tanto, será utilizado elementos da pesquisa empírica realizada com os grupos de catadores organizados em Alagoas durante o VI Encontro Estadual de Catadores de Materiais Recicláveis. Além desta introdução, na primeira seção abordar-se-á o conceito de economia solidária e as diferentes interpretações sobre sustentabilidade e a interação entre esses dois arcabouços. Na segunda seção, apresentar-se-á o levantamento da pesquisa em construção considerando os conceitos de economia solidária e sustentabilidade no estado de Alagoas. Por último, as considerações finais.

\section{A ECONOMIA SOLIDÁRIA E O TRABALHO ASSOCIADO COMO FERRAMENTA DE LUTA}

A utilização do excedente econômico pela classe dominante raramente se dá através de investimento na produção industrial, pois a classe dominante "encontram sempre melhores oportunidades de lucros na compra de terras já arrendadas, no exercício de atividades complementares à operação de empresas estrangeira, nos negócios de importação e exportação, no empréstimo de dinheiro e em especulações diversas" (BARAN, 1983, p. 161).

O Brasil é uma expressão desse exemplo, que tem se especializado na exportação de commodities agrícolas e minerais, principalmente para a Ásia. Avaliando-se a variação anual do volume de exportação (gráfico 1) no período de 2003-2011 percebe-se que a diminuição da quantidade exportada é compensada pelo aumento dos preços, de modo que o boom das exportações brasileiras se deu em termos de aumento de preços e não da quantidade exportada, porém a partir de 2012-2015 os preços passam a cair vertiginosamente, período no qual o Brasil passou por problemas econômicos e políticos.

Além disso, de acordo com Pereira \& Souza (2011), ocorreu uma "reprimarização" da pauta de exportação brasileira movida pela elevação do preço das commodities no comércio mundial, pois em 1999 os produtos manufaturados eram responsáveis por 57\% do total exportado pelo país, enquanto que os produtos básicos (commodities primárias: soja em grão, café em grão e minério de ferro) respondia por 25\%, enquanto que no ano de 2010 as exportações de manufaturados caíram para 39,5\%, e há uma elevação nas exportações dos produtos básicos para 44,6\%. E, mesmo assim, não foi utilizado esse excedente econômico para aumentar a produtividade da indústria, que é o principal setor responsável pela geração de emprego.

REVISTA ECONOMIA POLÍTICA DO DESENVOLVIMENTO $\quad$ Maceió - AL $\quad$ V.5 N.8. $\quad$ DEZEMBRO/2018 P.86-96 Página-87


Gráfico 1 - Variação anual (\%) dos índices de preços e quantidades das exportações brasileiras.

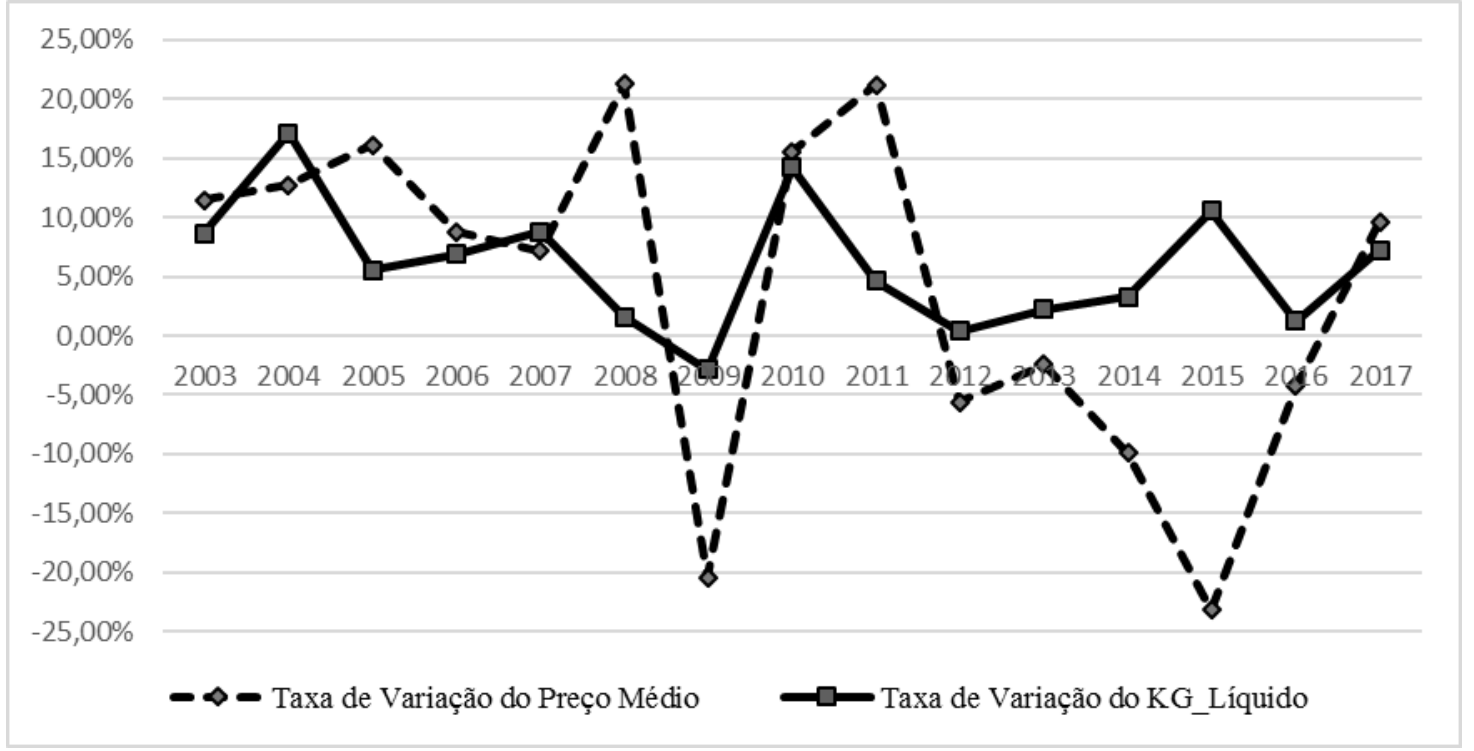

Fonte: MDIC (2018), elaboração própria.

A exploração e uso do solo de forma frenética e a monocultura pode gerar um excedente econômico que, se bem empregado, poderá contribuir para o desenvolvimento das forças produtivas, podendo elevar o nível de vida da população. Porém, a realidade que se vê nas nações periféricas é o fenômeno da dualidade dentro das nações subdesenvolvidas, na visão de Furtado (1968), na qual se encontra centros industriais tecnológicos, convivendo harmonicamente com a produção atrasada de baixa intensidade de capital, vivenciada pela maior parcela da população. Na visão do autor, o desenvolvimento econômico deve ser entendido como um processo mais amplo e complexo, de dimensão histórica autônoma na qual aspectos culturais estão envolvidos, como por exemplo, no padrão de consumo imitativo e conspícuo, especialmente da elite, das nações periféricas.

A caracterização de países em: desenvolvidos e subdesenvolvidos, não leva em consideração aspectos não econômicos, como exemplo, a utilização sustentável do meio ambiente, a preservação da biodiversidade e o consumo consciente. Deste modo, o pensamento ambientalista cresceu como reação ao crescimento econômico, porém não é correto afirmar que todos os ambientalistas se opõem ao crescimento econômico. De modo que, algumas correntes até o defendem sob promessas de desenvolvimento tecnológico. Existem diferentes visões acerca do entendimento do desenvolvimento sustentável, pode-se definir três correntes principais desta abordagem: "o culto ao silvestre", o "evangelho da ecoeficiência" e "o ecologismo dos pobres" (ALIER, 2007).

O culto ao silvestre é a defesa da natureza intocada, o respeito aos bosques primários e aos cursos d'água. Não ataca o crescimento econômico, porém coloca em discussão uma "ação de retaguarda", buscando proteger da influência de mercado o que resta da natureza, a fim de frear a $\begin{array}{llllll}\text { REVISTA ECONOMIA POLÍTICA DO DESENVOLVIMENTO } & \text { Maceió - AL } & \text { V.5 N.8. } & \text { DEZEMBRO/2018 } & \text { P.86-96 } & \text { Página-88 }\end{array}$ 
perda da biodiversidade. A principal proposta política dessa corrente do ambientalismo consiste em manter reservas naturais, também conhecida como parques nacionais ou naturais, livres da interferência humana. Como forma de medir a pressão humana sobre o meio ambiente, utiliza-se do índice de Apropriação Humana da Produção Primária Líquida de Biomassa (AHPPL).

A segunda corrente do pensamento ecologista, o evangelho da ecoeficiência, se preocupa com a economia na sua totalidade, defende o crescimento econômico, mas não a qualquer custo. De modo que, acredita no desenvolvimento sustentável, na modernização ecológica e na boa utilização dos recursos, preocupando-se com os impactos da produção de bens e com a utilização sustentável dos recursos naturais e, diferentemente do culto ao silvestre, não possui tanto interesse pela perda dos atrativos da natureza ou dos seus valores intrínsecos. Esta teoria tem dominado os debates ambientais, sociais e políticos, utiliza o conceito das "curvas Ambientais de Kuznets", pela qual o aumento de investimento gera, em primeiro lugar, o aumento da contaminação, mas em momentos seguintes levará a sua redução, ou seja, a busca de soluções de ganhos econômicos e ganhos ecológicos. Assim, afirmam que as mudanças tecnológicas tornarão compatível a produção de bens com a sustentabilidade ecológica, preservando parte da natureza que se mantém fora da economia. Entende-se, portanto, que as duas primeiras escolas se cruzam e entrelaçam em diversos momentos.

Uma terceira corrente ecologista tem desafiado essas duas primeiras, conquistando notoriedade, e é conhecida como "ecologismo dos pobres", "ecologismo popular" ou "movimento de justiça ambiental". Assinala que o crescimento econômico implica maiores impactos no meio ambiente, chamando a atenção para o "deslocamento geográfico das fontes de recursos e das áreas de descarte dos resíduos". De modo que os países desenvolvidos, para manter seus padrões de consumo, dependem cada vez mais das matérias-primas exportadas pelos países periféricos, gerando impactos que não são solucionados pelas políticas econômicas ou por inovações tecnológicas (ALIER, 2007, p. 33 e 34).

Neste sentido, grupos sociais têm protestado e resistido ao avanço da espoliação dos recursos naturais dos países periféricos, apelando para causas como o direito dos indígenas, camponeses e quilombolas (no caso brasileiro). O interesse desta terceira corrente não é o culto ao sagrado, mas um interesse material pelo meio ambiente como fonte de condição para a subsistência. A preocupação inicial não está ligada a causa ambiental, da preservação das espécies ou das gerações futuras, mas sim uma preocupação com os humanos pobres de hoje, demandando por justiça social contemporânea entre os humanos.

Neste sentido, encontramos diversos pontos de ligação da corrente da ecologia popular com o surgimento da economia solidária. Apesar de surgirem em espaços distintos, ambos estão pautados na contestação social e construção de práticas alternativas REVISTA ECONOMIA POLÍTICA DO DESENVOLVIMENTO V Maceió - AL $\quad$ V.5 N.8. $\quad$ DEZEMBRO/2018 P.86-96 Página-89 
ao modo de produção vigente, a princípio como forma de geração de trabalho e renda, viabilização econômica da agricultura familiar ou apenas forma de subsistência de uma minoria abastada pelo capitalismo, apresentam em si uma série de temas que remetem sobre as possibilidades de construção de formas de vidas sustentáveis. De modo que as experiências vivenciadas pelos Empreendimento Econômicos Solidários (EES) de catadores de materiais recicláveis apresentam estratégias criativas de mobilização de recursos, na produção de novas formas da organização do trabalho e o desenvolvimento de capacidades e vínculos que não são evidenciados na execução do trabalho individual.

A economia solidária pode ser definida como um modo de produção que surge devido às contradições do sistema capitalista e da impossibilidade deste de abarcar a todos os indivíduos dentro das atividades econômicas: produção, distribuição e consumo. Seus princípios são baseados em valores pautados na solidariedade, igualdade, democracia e na dignificação dos indivíduos, para tanto se faz necessária à igualdade dos sujeitos, tanto nos direitos quanto no aspecto econômico, tendo a autogestão como forma de organização do sistema de economia solidária (SINGER, 2002).

A economia solidária ressurge a partir do ano 1970 como resposta a crise econômica e desemprego em massa, período que coincide com o fim dos "anos dourados" do capitalismo, derrota da socialdemocracia, retrocesso de direitos da classe trabalhadora, transferência do capital financeiro para regiões que possuía pouca, ou nenhuma, proteção ao trabalhador. Este período também é marcado pela retomada da organização sindical dos trabalhadores e mobilizações pela obtenção e avanço de direitos da classe e, ainda, pelo volta a democracia e o fim do regime militar na América Latina (GAIGER, 2012).

Esta crise do modelo de bem-estar social atinge não somente a Europa, mas também transfere sérias consequências as economias da América Latina durante as décadas de 1980, conhecida como década perdida, na qual sofre o processo de concordata e falimentar de indústrias, inclusive de grande porte. $\mathrm{O}$ processo de fechamento e demissão dos trabalhadores prossegue pela década seguinte (SINGER, 2002).

É neste contexto que os movimentos sociais observam na solidariedade uma alternativa para superação dessas dificuldades. Em ambientes diferentes, organizações coletivas, como sindicatos, movimentos de trabalhadores sem-terra e pastorais das igrejas, retomam e reinventam as práticas do cooperativismo. A partir de experiências exitosas nos municípios de Belo Horizonte -MG, Porto Alegre - RS e Santo André - SP e Diadema - SP, passou-se a estimular a criação de novas organizações coletivas de catadores de materiais recicláveis no final da década de 1990 (AMORIM, 2012). 
Os catadores de lixo têm contribuído para a sustentabilidade e preservação do meio ambiente, realizam este trabalho não preocupados com as gerações futuras, ou por cultuarem a natureza, mas com a sobrevivência e a reprodução da vida. Apesar da recente notoriedade da categoria, formam a base mais excluída economicamente da pirâmide social brasileira, e encontram na solidariedade e autogestão as ferramentas de luta para a superação da miserabilidade. Estes são uma classe com níveis de baixa escolaridade e qualificação profissional, elevada faixa etária, com jornadas de trabalho extensa, ganhos abaixo do salário mínimo e trabalhando em condições insalubres.

A alternativa encontrada para mitigar essas condições adversas é a solidariedade e a autogestão, na qual a economia solidária se transforma no elemento da constituição de melhora de vida dos catadores. Amorim (2012) apresenta que o trabalho coletivo e a mobilização política permitem que os catadores melhorem sua autoestima e avancem na cadeia produtiva da reciclagem, destacando a importância da política pública como ferramenta de emancipação social destes.

Neste mesmo sentido, Moura, Serrano \& Guarnieri (2016) destacam o papel da coleta seletiva solidária e da organização no trabalho associado como ferramentas importantes na melhoria do trabalho decente e do reconhecimento social da profissão. A autogestão, desta forma, é a garantia de emprego e renda para esta categoria profissional, especialmente aos que não poderão mais catar nos lixões a céu aberto, devido a implementação da Política Nacional de Resíduos Sólidos (PNRS).

Do ponto de vista de reconhecimento enquanto categoria, pode-se destacar que a partir dos anos 2000 os catadores saíram de uma condição de inexpressividade para protagonistas de políticas sociais e ambientais, como pode ser observado na figura 1.

Figura 1: Linha do tempo marco legal e políticas públicas dos catadores de materiais recicláveis

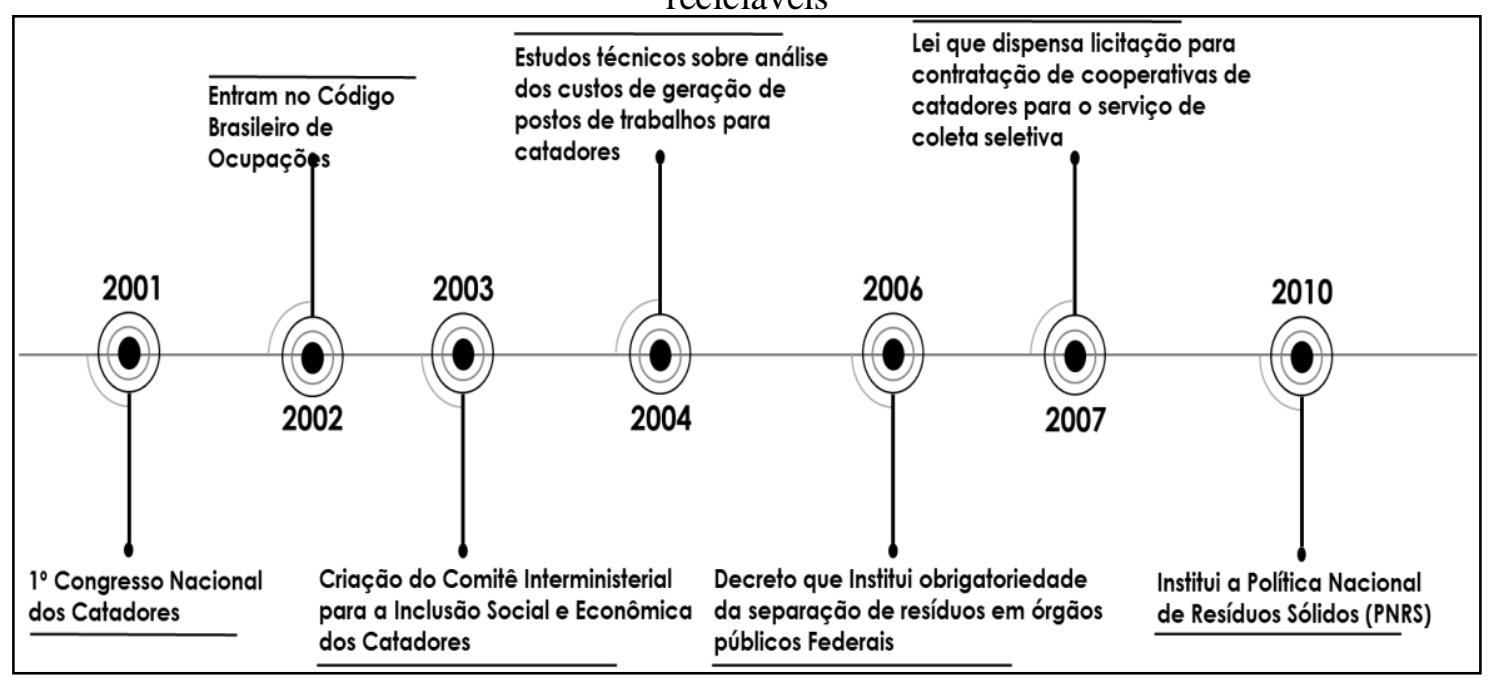

Fonte: Amorim (2012), elaboração própria. 


\section{AS PRÁTICAS ECONÔMICA E ECOLÓGICA DOS CATADORES DE MATERIAIS RECICLÁVEIS DE ALAGOAS}

A PNRS está vigente no Brasil desde 2010, e determina que os vazadouros a céu aberto deveriam ter suas atividades encerradas até dezembro de 2014. Porém, diversos municípios não conseguiram cumprir o prazo legal, de modo que, das cidades alagoanas, somente Maceió havia iniciado o processo de destinação ambientalmente adequado dos seus resíduos sólidos. Porém, em 2016 com intervenções do Ministério Público de Alagoas MP/AL e do Instituto do Meio Ambiente de Alagoas - IMA/AL algumas cidades do interior deram inicio ao encerramento das atividades dos mesmos. Até maio de 2017 havia sido encerado 28 lixões, passando os municípios a destinarem seus resíduos para as Centrais de Tratamento de Resíduos (CTR) do município de Pilar e Craíbas, bem como no aterro sanitário em Olho D’Água das Flores. As demais prefeituras fizeram um Termo de Ajustamento de Conduta (TAC) com o MP/AL com prazos para cumprimento da lei.

O estado de Alagoas tem adotado medidas para cumprir a legislação ambiental. Porém, observando pela ótica social, diversas famílias, excluídas pelo sistema de mercado, retiram seu sustento da catação de lixo, e precisam de políticas públicas que contribuam para o momento de transição entre o fim do trabalho nos vazadouros a céu aberto, para o trabalho da coleta seletiva solidária.

O relatório do IPEA (2013) que trata da situação socioeconômica dos catadores de materiais reciclável e reaproveitável do Nordeste mostra que existem 8.294 catadores no estado de Alagoas, destes 33,6\% são mulheres, 74,4\% de negros (pretos e pardos) e 88,9\% são residentes de áreas urbanas. A taxa de analfabetismo é de 41,3\% e possuem um rendimento médio de $\mathrm{R} \$ 455,40$, acerca das condições de moradia dos catadores, $75,6 \%$ deles residem em locais sem esgotamento sanitário adequado e apenas $17,1 \%$ de crianças (0 a 3 anos) residentes em domicilio com ao menos 1 catador que frequentam creche. Porém, por se tratar de uma profissão predominantemente informal é uma ocupação com uma grande facilidade de entrada e saída, esse número pode elevar-se com crises econômicas e aumento do desemprego.

O plano estadual de resíduos sólidos de Alagoas apresenta alguns indicadores que dimensiona as condições insalubres de residência e a falta de políticas públicas para essa classe, que por morarem próximo aos lixões, facilita o acesso de crianças a este tipo de trabalho. A tabela 1, abaixo, apresenta mais informações sobre locais de atuação e moradia dos catadores alagoanos. 
Tabela 1. Indicadores Sobre Locais de Atuação e Moradia dos Catadores de Materiais Reutilizáveis e Recicláveis no Estado de Alagoas

\begin{tabular}{|c|c|c|c|c|c|c|}
\hline Região & $\begin{array}{c}\mathrm{N}^{\mathbf{o}} \text { de } \\
\text { catadores } \\
\text { morando } \\
\text { próximo } \\
\text { ao lixão } \\
\end{array}$ & $\begin{array}{c}\mathrm{N}^{\circ} \text { de } \\
\text { catadores } \\
\text { trabalhando } \\
\text { no lixão }\end{array}$ & $\begin{array}{c}\mathrm{N}^{\mathbf{o}} \text { de } \\
\text { catadores } \\
\text { trabalhando } \\
\text { na rua }\end{array}$ & $\begin{array}{c}\mathbf{N}^{0} \text { Total } \\
\text { de } \\
\text { catadores }\end{array}$ & $\begin{array}{c}\mathrm{N}^{0} \text { de } \\
\text { crianças } \\
\text { trabalhando } \\
\text { no lixão }\end{array}$ & $\begin{array}{c}\mathrm{N}^{0} \text { de } \\
\text { crianças } \\
\text { morando } \\
\text { próximo } \\
\text { ao lixão } \\
\end{array}$ \\
\hline Agreste Alagoano & 184 & 331 & 164 & 495 & 20 & 71 \\
\hline Bacia Leiteira & 0 & 65 & 18 & 83 & 2 & 0 \\
\hline Litoral Norte & 2 & 28 & 23 & 51 & 2 & 0 \\
\hline Metropolitana & 0 & 69 & 103 & 172 & 6 & 0 \\
\hline Sertão & 5 & 61 & 64 & 125 & 1 & 0 \\
\hline Sul do Estado & 0 & 76 & 49 & 125 & 0 & 0 \\
\hline Zona da Mata & 3 & 129 & 79 & 208 & 0 & 0 \\
\hline Alagoas & 194 & 759 & 500 & 1.259 & 31 & 71 \\
\hline
\end{tabular}

Fonte: SEMARH, 2015.

Além dos catadores que trabalham nos lixões e nas ruas, há os que encontraram na autogestão e solidariedade uma forma de superação da exclusão social e ferramenta de luta para busca do trabalho decente. Em Alagoas, existem pelo menos 14 organizações coletivas de catadores, que geram renda para cerca de 258 famílias. Os Empreendimentos Econômicos Solidários (EES) de catadores apresentam níveis diferentes de organização e estrutura, os da capital são superiores nestes termos, porém todos apresentam histórias de luta e resistência pela sobrevivência e manutenção de seus trabalhos.

A coleta seletiva solidária têm sido a ferramenta encontrada para a manutenção do trabalho dos catadores de Maceió após o encerramento dos lixões. Esta é uma tecnologia social criada pela categoria e que tem permitido avançar na cadeia produtiva da reciclagem, para tanto contam com o apoio de outras organizações sociais e da adesão da população para separarem seus resíduos recicláveis. Apesar disso, os catadores ainda dependem de intermediários, que compram a produção para revenderem as indústrias, de modo que os catadores compõem o elo mais frágil, porém o mais importante, da cadeia produtiva da reciclagem.

Somente as cooperativas de catadores de Maceió possuem contrato remunerado com o poder público para prestação do serviço de coleta seletiva, que permitiu aumentarem os postos de trabalho e suas rendas, e ainda, permitindo que os catadores tenham maior autonomia no gerenciamento de seus empreendimentos. Diferentemente dessas, as demais organizações de catadores não possuem nenhum contrato remunerado, e lutam em busca de locais de trabalho, reconhecimento e políticas públicas, desde a implantação da coleta seletiva até o pagamento pelo serviço prestado. 
Quadro 1. Cooperativas e Associações de Catadores de Alagoas

\begin{tabular}{|c|c|c|c|}
\hline Cooperativas/Associações & Associados & $\begin{array}{l}\text { Quant. } \\
\text { (ton) }\end{array}$ & Município \\
\hline Associação dos Catadores de Delmiro - ASCADEL & 34 & 12 & $\begin{array}{l}\text { Delmiro } \\
\text { Gouveia }\end{array}$ \\
\hline $\begin{array}{l}\text { Associação dos Catadores de Arapiraca - } \\
\text { ASCARA }\end{array}$ & 09 & 15 & Arapiraca \\
\hline $\begin{array}{l}\text { Associação dos Catadores e Catadoras de } \\
\text { Materiais Recicláveis São José - ASCAMARE }\end{array}$ & 15 & 10 & Coruripe \\
\hline $\begin{array}{l}\text { Associação dos Catadores de Materiais Recicláveis } \\
\text { - ACAMARE }\end{array}$ & 13 & 15 & $\begin{array}{l}\text { São } \\
\text { Miguel } \\
\text { dos } \\
\text { Campos }\end{array}$ \\
\hline $\begin{array}{l}\text { Associação de Catadores e Recicladores do } \\
\text { Município de Piranhas - ASCARPI }\end{array}$ & 14 & 08 & Piranhas \\
\hline $\begin{array}{l}\text { Associação de Catadores de Mata Grande, Inhapi e } \\
\text { Canapi - ASCAMIC }\end{array}$ & 18 & 14 & Inhapi \\
\hline $\begin{array}{l}\text { Cooperativa dos Catadores de Materiais } \\
\text { Recicláveis de Campo Alegre - COOPECMARCA }\end{array}$ & 08 & 25 & $\begin{array}{l}\text { Campo } \\
\text { Alegre }\end{array}$ \\
\hline $\begin{array}{l}\text { Cooperativa dos Catadores da Vila Emater - } \\
\text { COOPVILA }\end{array}$ & 35 & 20 & Maceió \\
\hline $\begin{array}{l}\text { Cooperativa dos Recicladores de Alagoas - } \\
\text { COOPREL }\end{array}$ & 18 & 16 & Maceió \\
\hline $\begin{array}{l}\text { Cooperativa dos Recicladores de Alagoas - } \\
\text { COOPREL Benedito Bentes }\end{array}$ & 32 & 15 & Maceió \\
\hline $\begin{array}{l}\text { Cooperativa de Recicladores de Lixo Urbano de } \\
\text { Maceió - COOPLUM }\end{array}$ & 18 & 15 & Maceió \\
\hline $\begin{array}{l}\text { Associação dos Catadores de Materiais Recicláveis } \\
\text { de Palmeira dos Índios - ASCAMRPI }\end{array}$ & 14 & - & $\begin{array}{l}\text { Palmeira } \\
\text { dos Índios }\end{array}$ \\
\hline $\begin{array}{l}\text { Cooperativa dos Catadores de Materiais } \\
\text { Recicláveis Marechal Deodoro - COOPMAR }\end{array}$ & 10 & - & $\begin{array}{l}\text { Marechal } \\
\text { Deodoro }\end{array}$ \\
\hline $\begin{array}{l}\text { Associação dos Catadores de Materiais Recicláveis } \\
\text { de Mangabeiras-ASCAMAM }\end{array}$ & 20 & - & Arapiraca \\
\hline
\end{tabular}

Fonte: Entrevista com lideranças dos catadores e SEMARH (2015). Elaboração do autor.

Como forma de cobrar e propor políticas públicas os catadores se organizam como movimento social a nível nacional através do Movimento Nacional dos Catadores de Materiais Recicláveis (MNCR) e sua representação a nível estadual, em novembro de 2016, organizaram o VI encontro estadual de catadores de Alagoas. Neste encontro estiveram presentes representantes de 12 municípios do estado, na qual apresentaram as necessidades de apoio para o fortalecimento de suas organizações e para o avanço da coleta seletiva solidária, ilustradas no Quadro 02. 
Quadro 02- Necessidades Apontadas no VI Encontro Estadual dos Catadores

\begin{tabular}{|l|l|}
\hline Eixos & Ações \\
\hline $\begin{array}{l}\text { Política Pública de } \\
\text { Apoio aos Catadores }\end{array}$ & $\begin{array}{l}\text { Programa de apoio à estruturação das cooperativas/associações; } \\
\text { Programa de coleta seletiva; Contratação das organizaçôes de } \\
\text { catadores; Vigilância contra incêndio nos lixões. }\end{array}$ \\
\hline Estrutura Física & Concessão de Terrenos; Construção/reforma de galpões. \\
\hline $\begin{array}{l}\text { Aquisição de máquinas } \\
\text { e equipamentos }\end{array}$ & $\begin{array}{l}\text { Veículos para coleta seletiva; Prensa; Balança; Mesa/esteira } \\
\text { para catação; fragmentadora de papel; Elevador de carga; } \\
\text { Empilhadeira; Computador; Telefone; Bebedouro. }\end{array}$ \\
\hline Assessoria Técnica & $\begin{array}{l}\text { Apoio jurídico e contábil para formalização; Capacitação } \\
\text { ambiental e econômica, no âmbito do cooperativismo; } \\
\text { Integração para funcionar em rede e Apoio a formação de } \\
\text { cooperativas. }\end{array}$ \\
\hline $\begin{array}{l}\text { Campanhas de } \\
\text { Comunicação }\end{array}$ & $\begin{array}{l}\text { Folder, panfletos, inserções no rádio e TV conscientizando a } \\
\text { população para a coleta seletiva, campanhas junto a empresas. }\end{array}$ \\
\hline $\begin{array}{l}\text { Aquisição de Materiais } \\
\text { de Consumo }\end{array}$ & $\begin{array}{l}\text { Aquisição de "bigbag" para coleta, material de limpeza e de } \\
\text { escritório, Fardamentos, Equipamentos de Proteção Individual } \\
\text { - EPIs, Bombonas etc. }\end{array}$ \\
\hline $\begin{array}{l}\text { Apoio para Despesas } \\
\text { Diversas }\end{array}$ & $\begin{array}{l}\text { Motorista, manutenção de maquinário, seguro para caminhão, } \\
\text { Combustível e em outros custos fixos. }\end{array}$ \\
\hline Isenção de Impostos & IMCS, IPVA, taxa de localização e outros. \\
\hline
\end{tabular}

Fonte: Elaboração do autor com informações do Movimento Estadual dos Catadores.

\section{CONSIDERAÇÕES FINAIS}

Por se tratar de uma pesquisa ainda em andamento, ainda há muitas lacunas e questões a serem levantadas e aprofundada, pois o concreto apresenta-se em construção e contínua mudança para ser pensado e repesando. Porém, podemos tecer algumas reflexões acerca do objeto estudado. A organização coletiva mostra-se como uma possibilidade de construção de um novo tipo de sociedade, não baseada na competitividade e nas relações monetárias, mas sim em práticas de autogestão, solidariedade, democracia e liberdade. Dessa forma, os catadores encontram na prática da autogestão uma ferramenta não só para superação da miserabilidade e criação de empregos de baixo valor agregado, mas da perspectiva do crescimento na sua cadeia produtiva, com possibilidades de agregar valor ao seu produto e adentrar a escalas industriais.

A pesquisa ilustra que os catadores de materiais recicláveis estudados não são agentes ambientais, que realizam seu trabalho a fim da preservação do meio ambiente ou preocupados com a sobrevivência com as gerações futuras. Desenvolvem suas atividades em meio a um sistema excludente, apresentam suas críticas e revolucionam esse sistema na medida que sobrevivem em meio a prática da autogestão, produzindo sem competir ou explorar seus pares. Mesmo assim, é necessário se pensar políticas públicas que deem subsídios a estas práticas não só como forma de geração de renda e sim como forma emancipatória desta sociedade excludente com consciência ambiental. 


\section{REFERÊNCIAS}

ALIER, Juan Martínez. O Ecologismo dos Pobres. São Paulo: Contexto, 2007.

AMORIM, L. S. Economia solidária e catadores de materiais recicláveis em Salvador e Curitiba: políticas públicas e a enunciação de identidades no Brasil. Revista Avaliação de Políticas Públicas (AVAL), Fortaleza, ano 5, v. 2, n. 10, p. 21-35, jul./dez. 2012.

BARAN, Paul. Economia Política do Desenvolvimento. Coleção Os Economistas. São Paulo: Abril Cultural, 1983.

FURTADO, Celso. Teoria e Política do Desenvolvimento Econômico. 2 ed. São Paulo: Editora Nacional, 1968.

MDIC - Ministério da Indústria, Comércio Exterior e Serviços. Base de dados do comércio exterior brasileiro. 1997-2018. Brasília. Disponível em: < https://goo.gl/euvpDk >. Acesso em: 03/03/2018.

MOURA, G. R.; SERRANO, A. L. M.; GUARNIERI, P. Análise socioeconômica dos catadores de materiais recicláveis no Distrito Federal. Holos, Rio Grande do Norte, v. 3, n. 32, p. 251-273, abr. 2016. Disponível em: <http://www2.ifrn.edu.br/ojs/index.php/HOLOS/article/view/1857/pdf>. Acesso em: 01 fev. 2018

PEREIRA, Lia Vallz; SOUZA, André Luiz Silva de. "Exportações brasileiras na primeira década do século XXI: desempenho e fonte de crescimento". In: BONELLI, Regis (org.). A agenda de competitividade do Brasil. Rio de Janeiro: FGV, p. 323-377, 2011.

SEMARH - Secretaria de Estado do Meio Ambiente e dos Recursos Hídricos. Resíduos Sólidos Alagoas. Disponível em: <<http://www.residuossolidos.al.gov.br/>>. Acesso em 10 de Maio de 2017.

SINGER, Paul. Introdução à Economia Solidária. 1ª Ed. São Paulo: Fundação Perseu Abramo, 2002. 